\title{
Correction to: A scoping review of Critical Predictive Factors (CPFs) of satisfaction and perceived learning outcomes in E-learning environments
}

\author{
Abdullahi Abubakar Yunusa ${ }^{1,2,3} \cdot$ Irfan Naufal Umar $^{1}$ \\ Published online: 11 September 2020 \\ (C) Springer Science+Business Media, LLC, part of Springer Nature 2020
}

\section{Correction to: Education and Information Technologies https://doi.org/10.1007/s10639-020-10286-1}

The published version of this article unfortunately contains incorrect affiliation information.

The second author, Professor Irfan Naufal Umar was tagged as affiliated to 2(Department of Curriculum Studies and Educational Technology, Usmanu Danfodiyo University, Sokoto, Nigeria) instead of affiliation 1(Centre for Instructional Technology \& Multimedia (CITM), Universiti Sains Malaysia. The corrected affiliation label is presented in this erratum.

Publisher's note Springer Nature remains neutral with regard to jurisdictional claims in published maps and institutional affiliations.

The online version of the original article can be found at https://doi.org/10.1007/s10639-020-10286-1

Abdullahi Abubakar Yunusa

abdullahi.yunusa@udusok.edu.ng

Irfan Naufal Umar

irfan@usm.my

1 Center for Instructional Technology \& Multimedia, Universiti Sains Malaysia, 11800 George Town, Penang, Malaysia

2 Department of Curriculum Studies \& Educational Technology, Usmanu Danfodiyo University Sokoto, Sokoto, Nigeria

3 Center for Multidisciplinary Research and Innovation (CEMRI), Suite C59, New Banex Plaza, Wuse 2, Abuja, Nigeria 